DOI: 10.14526/2070-4798-2020-15-3-42-47

\title{
Psychological maintenance in kettlebell lifting
}

\author{
Bazanov A.N.* \\ Saint-Petersburg State University of Telecommunications named after professor M.A. Bonch-Bruevich \\ Saint-Petersburg, Russia \\ ORCID: oooo-ooo2-7016-3281, a.bazanovvv@mail.ru*
}

\begin{abstract}
The urgency of the held research work is conditioned by the desire to improve the quality of training athletes-weightlifters for the future competitions, owing to the quality of their psychological readiness improvement. Material. Studying the influence of auto-training on psycho-emotional state of students, who go in for kettlebell lifting, their physical readiness for the future work realization. Research methods: clinical-biographical method, joint discussion method, method of talk therapy, the method of own important feelings recording in a diary, the method of an athlete's diary correction, observation method (especially in crisis). Result. Autotraining was held during the term with the members of kettlebell lifting University team and students, who go in for kettlebell lifting as an elective course. Using different research methods we tried to regulate stage by stage psychological maintenance of weightlifters. Especially effective was auto-training. The results of the performances improved and it proves the necessity to continue and develop the work in this direction. Conclusion. Auto-training (AT) has a positive influence on psychological state of athletes and the results of their performances. At the same time, it is important to remember that this is only insignificant part of psychological training and psychological maintenance.
\end{abstract}

Keywords: important feelings, crisis, individual potential of overcoming, pre-start fear, motivation, self-assessment, concentration, counter-dominant.

For quotation: Bazanov A.N.* Psychological maintenance in kettlebell lifting. Journal of Physical Education and Sport. 2020; 15(3): 33-36. DOI: 10.14526/2070-4798-2020-15-3-42-47

\section{INTRODUCTION}

Nowadays great attention in sport is paid to psychological training of athletes. Very often during the competitions an athlete can't show the result, which he showed easily during the training lessons. It proves mainly psychological character of his failures.

Success in sport in general and in kettlebell lifting in particular mainly depends on the ability of an athlete to overcome crisis, especially in extreme conditions of official competitions.

The urgency of the problem is in the importance and necessity to teach athletes overcome any difficulties they face while achieving the set aim. Obstacles can be inner (negative states, fear, uncertainty, tiredness), athletes overcome them during the struggle with oneself, and external (an opponent's resistance, unfavorable conditions of activity, for example, referee and spectators bias, interaction with close to sport environment and etc.), which a person overcomes during his main activity fulfillment [1].

The article considers only the questions connected with auto-training and its influence on weightlifters, in terms of clear understanding of detailed, systematic and professional psychological maintenance of athletes-weightlifters. The article is about sport for students, which conditions specificity of psychological training, psychological maintenance. Student sport as mass sport gives an opportunity to develop own physical qualities and motor abilities, strengthen health state and resist undesirable influence of everyday life conditions on an organism. The aims of going in for mass kinds of sport and kettlebell lifting in particular, are the following: health improvement, positive moral qualities upbringing, healthy life style organization, physical development improvement, active rest [2]. Directing own efforts toward these aims realization we should mention that the desire to get the first place among athletes and coaches is great, but there are differences in motivational sphere, in the sphere of significant feelings and crises, in comparison with student sport and professional sport. There are, undoubtedly, general regularities.

Thus, taking into consideration all 
mentioned above, we realized the work the aim of which is studying the influence of auto-training on psycho-emotional state of students, who go in for kettlebell lifting, their physical readiness to the future work fulfillment.

\section{MATERIALS AND METHODS}

The work was held on the basis of SaintPetersburg University of Telecommunications named after professor M.A. Bonch-Bruevich with 37 students ( 28 boys and 9 girls) within the age range 18-23, who were the members of kettlebell lifting University team and the students, who go in for elective courses according to "Kettlebell lifting and athletic training" program during the term. Autotrainings were held with this group of students, both mutual and individual ones, in different situations and on different stages of training for the competitions. Using "consciousness and activity" principle we discussed the aims and objectives of the experiment, transitional results of the work, personal observations of athletes and their desires concerning auto-trainings (AT) organization with the students. As a result, we managed to increase the interest of athletes in the fulfilled work, its importance realization personally for them. During the work the methodology of AT organization changed. It was mainly connected with the separate auto-training formulas and some time-parameters. We optimized the duration of AT, time of AT organization before the start, time interval between auto-training formulas.

We used the following research methods: clinical-biographical method, joint discussion method, method of talk therapy, the method of own important feelings recording in a diary, the method Table 1 - Psycho-types of weightlifters from the expe of an athlete's diary correction, observation method (especially in crisis).

The presented methods use solves the problem of the influence on an athlete: it improves mood, increases athlete's self-appraisal and selfconfidence, prevents the influence of negative emotions and the accumulated dissatisfaction (catharsis).

Taking into account that the most widelyspread in this group of respondents was such crisis, as "prestart fever", less frequently "prestart apathy", we held the auto-training in order to optimize emotional state of weightlifters before the start for making them ready. The effectiveness of AT was estimated according to the results of an athlete's performances during different competitions, control starts. An athlete's results of the performances were compared with his personal achievements (personal records). The athlete also estimated own performance and own psycho-emotional state before the start, during the start, during the competitive exercise fulfillment.

\section{RESEARCH RESULTS AND DISCUSSION}

Crises, which an athlete experiences, almost always have negative influence on the results of his performances, the training process and the whole life in general. They mainly appear because of inability to cope with considerable feelings, make worries less significant, make them constructive and then insignificant.

In spite of not great life experience of the respondents we had the necessity to use clinicalbiographical method. With the help of this method the experimental group was divided into psycho types (Zagaynov R.M. classification, 2010):

\begin{tabular}{|c|l|c|}
\hline Psycho-type & \multicolumn{1}{|c|}{ Short characteristic } & $\%$ \\
\hline $\begin{array}{l}\text { Type 1 - "well- } \\
\text { doer" }\end{array}$ & $\begin{array}{l}\text { "Positive" motivation, very high (the sense of responsibility, honor, } \\
\text { patriotism and other moral values prevail). }\end{array}$ & 24 \\
\hline Type 2 - "one-aloner" & $\begin{array}{l}\text { "Negative" motivation, very high (negativism in terms of people } \\
\text { and life, sense of anger toward the opponent, individualism and } \\
\text { mercantilism prevail). }\end{array}$ & 8 \\
\hline Type 3 - "artistical" & $\begin{array}{l}\text { Mainly "positive" motivation, not high (external impediments } \\
\text { of sport and sports competition motivate such an athlete: stage, } \\
\text { auditorium, publicity of his life and activity, the element of creativity } \\
\text { of the activity itself, popularity). }\end{array}$ & 26 \\
\hline
\end{tabular}




\begin{tabular}{|c|l|c|}
\hline Type 4- "intellectual" & $\begin{array}{l}\text { Mainly "positive" motivation, not high (intellect is the base of his } \\
\text { activity and life, it is directed toward each situation and each action } \\
\text { understanding. Sport for the "intellectual" is proving range, where } \\
\text { he studies himself, own potentialities and gets ready for another } \\
\text { activity). }\end{array}$ & 32 \\
\hline Type 5- "fragile" & $\begin{array}{l}\text { Mainly "positive" motivation, not high (this psycho-type is formed as } \\
\text { a result of a happy childhood and further crisis-free life, he can't stand } \\
\text { rudeness, boorishness, dictatorate in work and communication. It is } \\
\text { difficult for this person to overcome any crisis, especially prestart } \\
\text { one. He is always afraid of defeat). }\end{array}$ & 10 \\
\hline
\end{tabular}

The research works showed that from 12 important feelings only 9 ones were urgent [3] for the studied group of weightlifters (table 2).

Table 2 - Important feelings of the athletes in \%

\begin{tabular}{|c|l|c|}
\hline № & \multicolumn{1}{|c|}{ Important feelings } & $\%$ \\
\hline 1 & Fear of defeat & 54 \\
\hline 2 & Feeling of dissatisfaction & 48 \\
\hline 3 & Feeling of uncertainty & 62 \\
\hline 4 & Feeling of responsibility & 56 \\
\hline 5 & Feeling of rivalry & 42 \\
\hline 6 & Feeling of burden of leadership & 2 \\
\hline 7 & Feeling of publicity (uneasiness) & 14 \\
\hline 8 & Feeling of the main and not main activity imbalance & 15 \\
\hline 9 & Feeling of psychological tiredness & 2 \\
\hline
\end{tabular}

According to psycho-types feelings were distributed the following way: type $1-2,4$; type $2-$ 1, 2, 4, 5, 6, 9; type $3-1,2,3,5,7$; type $4-2,3,4,7$, 8 ; type $5-1,2,3,4,5,7,8$.

Taking into account the received results, we tried to organize auto-training paying attention to individual characteristics of weightlifters. During several months the respondents gained the skills of making their psychophysical conditions optimal in different situations [4]. Auto-trainings were held in the groups before and after the training lessons with the help of the coach. Before going to bed athletes mastered the skills themselves. Then auto-trainings were held before the control starts and before the official competitions in kettlebell lifting.

We saw how athletes' sports results improved in terms of the increased psychological readiness and we mentioned some regularities in the crisis overcoming (pre-start, with the help of auto-training).

A lot of factors should be taken into account: starting from the conditions of an athlete's educational-training activity during the day, week, month, longer period, time and date of competitions till psychological peculiarities of a personality; dynamics of bioenergetics potential change during the day; the aims, set for the given training lesson (several trainings); health state and the degree of rehabilitation of an athlete at the present moment $[5,6,7,8,9]$.

A day before the competitions, especially the day of competitions should be planned. An athlete should be always busy. It means helping the members of the team, who have earlier performances (dumbbells preparation, psychological support), taking photo, watching the performances of the athletes from other teams. AT organization in a team with the coach and before warming-up independently. Warming-up directly before the start. It decreases the possibility to have negative thoughts and emotions.

A coach should always watch the athletes of the whole team. An athlete shouldn't stay alone.

The specificity of kettlebell lifting competitions should be taken into account. Competitions are long-term. Young men of heavy weight categories have to wait for a long time that is why great attention should be paid to them. Girls are in more favorable conditions, as they are the first to perform. As they are free after the performances 
their psychological support becomes more urgent for the other members of the team. The team should be together till the final performance.

Athletes should be in a constant "volitional corset", especially on the day of competitions. During warming-up there is the final mindset for the performance with maximal attention concentration.

AT presents the variant of autogenic training, which is adapted to the conditions of sports lessons (A.V. Alekseev, L.D. Gissen, 1969). Psychological basis of AT is attention focusing on the images and feelings, connected with muscles relaxation. At the same time, the formulas, which cause the sense of difficulty in the work with athletes, are not used. Moreover, the activating part of AT includes the formulas, which are specially directed toward this sense prevention, if it appears. AT has sequence of psycho-regulation formulas systematization (which has to be mastered).

We should also eliminate negative influence on an athlete, which can be from the group of psychological support (close people, friends), in order to prevent the effect of counter dominant, which violates concentration.

\section{CONCLUSION}

It should be noted that the methods and principles of sport psychology, different means in this sphere of knowledge should be used in student sport. Having no other opportunities this work has to be realized by the coach, who had to be in charge of psychological training of athletes (even intuitively). Psychological maintenance in student sport demands professional basis. Coaches and teachers should have the corresponding training and knowledge. If there is the opportunity to involve a professional sports psychologist, it is necessary to provide psychological maintenance of the teams in kinds of sport in a form of systematic consultations of a specialist.

AT has positive influence on psychological state of athletes, if it is correctly used, and on the results of athletes' performances. It should be taken into account that this is only insignificant part of psychological training and psychological maintenance.

\section{REFERENCES}

1. Zagaynov R.M. Crises in sport and psychology of their overcoming. Moscow: Soviet sport. 2010: 8. [In Russ.].

2. Ogorodova T.V. Psychology of sport: manual. Yaroslavl: Yaroslavl State University. 2013: 7. [In Russ.].

3. Zagaynov R.M. Psychology of modern sport of higher achievements. Moscow: Soviet sport. 2012: 62. [In Russ.].

4. Ganzhenko Yu.V., Bazanov A.N. Programed teaching during physical culture lessons at a higher educational establishment. Collection of articles of the II International scientific-technical and scientific-methodical conference "Urgent problems of info-telecommunications in science and education". Saint-Petersburg: Saint Petersburg State University of Telecommunications. 2013: 1063. [In Russ.].

5. Bazanov A.N. An optimal time selection for kettlebell lifting trainings organization. International journal of humanitarian and natural sciences. 2018; 11-1: $56-58$.

6. Aleksey V. Pushkarev* Psychological aspects of success and reliability demonstration among basketball players in competitive activity. Russian Journal of Physical Education and Sport. 2020; 15(2): 74-79. DOI: 10.14526/2070-47982020-15-2-92-98 [In Russ., In Engl.].

7. Aleksandr S. Kuznetsov, Zinaida $M$. Kuznetsova. II Congress of members of the public organization "Russian professorial Assembly». Russian Journal of Physical Education and Sport. 2019; 14(4): 5-7. DOI: 10.14526/2070-4798-201914-4-5-7 [In Russ., In Engl.].

8. Karipidis A., Fotinakis P., Taxildaris K., Fatouros J. Factors characterizing a successful performance in basketball. Journal of Human Movement Studies. 2001; 41: 385-397.

9. Schmidt A. Movement pattern recognition in basketball free-throw shooting. Human Movement Science. 2012; 31: 360-382. DOI: 10.1016/j.humov.2011.01.003.

\section{Submitted: 23.06.2020}

\section{Author's information:}

Bazanov Andrey Nikolaevich - senior teacher, Saint-Petersburg State University of Telecommunications named after professor M.A. Bonch-Bruevich, 193382, Russia, Saint- Petersburg, Bolshevikov avenue, House 22, e-mail: a.bazanovvv@mail.ru 